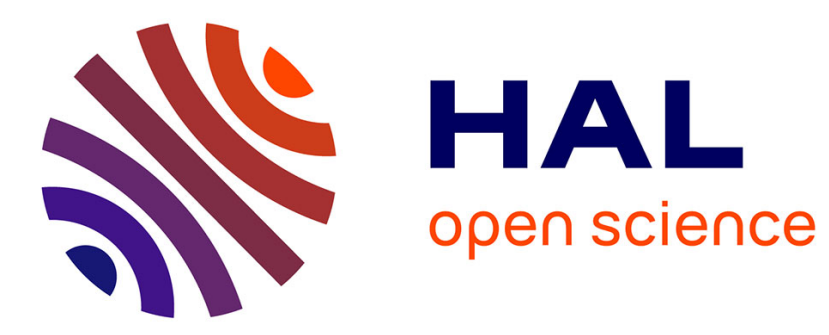

\title{
Infrared spectroscopic determination of poly(ethylene glycol) for nutritional studies
}

Claire Belleville, P. Robert, Christine Hoebler, J.L. Barry

\section{To cite this version:}

Claire Belleville, P. Robert, Christine Hoebler, J.L. Barry. Infrared spectroscopic determination of poly(ethylene glycol) for nutritional studies. Journal of Agricultural and Food Chemistry, 1995, 43 (10), pp.2672-2677. hal-02709111

\section{HAL Id: hal-02709111 https://hal.inrae.fr/hal-02709111}

Submitted on 1 Jun 2020

HAL is a multi-disciplinary open access archive for the deposit and dissemination of scientific research documents, whether they are published or not. The documents may come from teaching and research institutions in France or abroad, or from public or private research centers.
L'archive ouverte pluridisciplinaire HAL, est destinée au dépôt et à la diffusion de documents scientifiques de niveau recherche, publiés ou non, émanant des établissements d'enseignement et de recherche français ou étrangers, des laboratoires publics ou privés. 


\title{
Infrared Spectroscopic Determination of Poly(ethylene glycol) for Nutritional Studies
}

\author{
C. Belleville, P. Robert, ${ }^{*}$ C. Hoebler, and J. L. Barry \\ INRA, rue de la Géraudière, B.P. 1627, 44316 Nantes Cedex 03, France
}

\begin{abstract}
Markers are commonly used in nutritional studies to evaluate the transit and degradation rate of food. Poly(ethylene glycol) is a water-soluble marker that is poorly quantified by the turbimetric technique in some digestive samples. In the present work, an alternative for quantifying poly(ethylene glycol) was tested. In the mid-infrared region, poly(ethylene glycol) has a characteristic absorption band around $1080 \mathrm{~cm}^{-1}$ which increases with the poly(ethylene glycol) content. A prediction equation for the poly(ethylene glycol) was assessed by applying a principal component regression to infrared spectral data recorded between 900 and $1200 \mathrm{~cm}^{-1}$. The correlation coefficient and the standard error obtained were 0.99 and $0.29 \mathrm{~g} \mathrm{~L}^{-1}$, respectively. Samples resulting from an in vitro digestion of bread were submitted to this equation. The results showed that infrared spectroscopy could be a relevant technique for the measurement of poly(ethylene glycol). In addition, the soluble carbohydrates could be evaluated by mid-infrared spectroscopy.
\end{abstract}

\section{Keywords: Infrared spectroscopy; mathematical treatments; biological marker; poly(ethylene glycol)}

\section{INTRODUCTION}

Infrared spectroscopy can be used as an alternative to traditional methods for studying chemical changes in nutritional experiments. Prediction of the chemical composition by infrared spectroscopy usually involves mathematical and statistical analyses such as multiple regression analyses. This approach has been successfully applied to both human (Fredstrom et al., 1994; Norris and Kuenstner, 1994) and animal studies (Robert et al., 1989; Coleman and Murray, 1993; Cosgrove et al., 1994; Murray et al., 1994) for the degradation of substrates in the digestive tract. In the work presented, the efficiency of this analytical method for predicting the content of a marker substance used to follow food through the gastrointestinal tract was evaluated.

The ability of a food to supply nutrients to an organism depends on the chemical and physical characteristics of the food. These characteristics have an influence on the food transit through the different parts of the digestive tract. Gastric digestion corresponds to the first step determining the flow of food arriving into the intestine. For the past 20 years, numerous methods have, therefore, been proposed to measure the gastric emptying of the solid or liquid phases. Techniques involving the administration of a nonabsorbable marker have been widely used to evaluate both the transit (Malagelada, 1977; Jian et al., 1979; Weimer et al., 1981) and the degradation of food in the gastrointestinal tract (Flourié et al., 1988; Molis et al., 1992; Faisant et al., 1995). Nonabsorbable markers should be nondegradable in the digestive tract and easily quantifiable and must also present the same transit as the phase or component studied. The determination of the marker content makes it possible to assess the digestibility of food and to correct for any loss of material. The use of specific markers is, therefore, needed to study the behavior of a food in the gastrointestinal tract. Poly(ethylene glycol) (PEG 4000) is a water-soluble marker currently used in animal nutrition studies for the measurement of digestibility (Sperber et al., 1953; Hyden, 1966; Isikawa et al., 1968). Additionally, as
PEG poses no safety problems, it has been used by several authors to trace the aqueous phase of a meal during digestion (Malagelada, 1977; Kerlin and Phillips, 1983; Thomforde et al., 1985). It presents a way to evaluate the intestinal digestibility of processed starchy food (Molis et al., 1992; Faisant et al., 1995). A simple turbidimetric method to measure PEG concentration in digesta was developed by Hyden (1956). This method was unfortunately found to produce quantification errors (Smith, 1958; Laplace, 1972) when substances resulting from digestion interfered with the measurement of PEG. An improvement in the PEG determination was obtained by using labeled $\left[{ }^{14} \mathrm{C}\right] \mathrm{PEG}$ (Malagelada, 1977; Meerof et al., 1979). However, the use of $\left.{ }^{[14} \mathrm{C}\right] P E G$ in human experiments is forbidden for ethical reasons in France.

In the work presented, infrared spectroscopy was used to accurately predict PEG concentration in biological digesta. To avoid any destruction and preparation of the samples, a total attenuated reflectance cell was used. The study was carried out using PEG dissolved in different media such as pig gastric juice or bread supernatant digesta. A validation of the analytical method was achieved with an in vitro bucco gastric digestion of bread samples.

\section{MATERIALS AND METHODS}

Samples. Various PEG (PEG 4000, Merck) solutions were prepared in four different media: distilled water, fasting pig gastric juice supernatant, ground bread supernatant, and ground bread supernatant resulting from a pepsic digestion. For each medium, the PEG concentration ranged from 0 to 10 $\mathrm{g} \mathrm{L}^{-1}$ in $0.5 \mathrm{~g} \mathrm{~L}^{-1}$ intervals.

The gastric juice was obtained from three pigs fitted with gastric cannula. Stomachs of the pigs were washed with tap water and the gastric juice collected after a delay of $1 \mathrm{~h}$.

Ground bread supernatant was obtained from dried bread crumb (100 g, Barilla, Parma, Italy) impregnated with $79 \mathrm{~mL}$ of water. The wet bread was then ground in a meat mincer (Zyliss, Switzerland) fitted with a $6 \mathrm{~mm}$ screen mesh. Water was added to achieve a dry matter/liquid ratio of $0.22(\mathrm{w} / \mathrm{w})$. In the case of pepsic digestion, the wet ground bread was 
Table 1. Spectral Collection ${ }^{\alpha}$

\begin{tabular}{lll}
\hline \multicolumn{1}{c}{ medium } & \multicolumn{1}{c}{ code } & set \\
\hline aqueous solution & $\mathrm{PG}_{x ;} \mathbf{G L}_{x}$ & \\
gastric juice & $\mathrm{CA}_{x} ; \mathrm{CB}_{x}$ & $\mathbf{C}$ \\
& $\mathrm{CD}_{x} ; \mathrm{CE}_{x}$ & $\mathrm{~V}$ \\
milled bread supernatant & $\mathbf{P A}_{x}$ & $\mathbf{C}$ \\
& $\mathbf{P B}_{x}$ & $\mathrm{~V}$ \\
milled bread supernatant with pepsine digestion & $\mathrm{PC}_{x}$ & $\mathbf{C}$ \\
& $\mathrm{PD}_{x}$ & $\mathrm{~V}$ \\
in vitro bread digestion & $\mathbf{E A}_{y}$ &
\end{tabular}

a $\mathrm{C}$, calibration samples; $\mathrm{V}$, verification samples; $x$, integer number coding the PEG content $\left(00\right.$ corresponds to $0 \mathrm{~g} \mathrm{~L}^{-1}, 20$ corresponds to $\left.10 \mathrm{~g} \mathrm{~L}^{-1}\right) ; y$, digestion time in $\mathrm{min}$.

mixed with $\mathrm{HCl}(0.2 \mathrm{~N}$, dry matter/liquid ratio of 0.22$)$ and the pepsic digestion was carried out for $3 \mathrm{~h}$ under magnetic stirring by adding pepsin (73 400 Anson units/g of bread protein) purchased from Sigma (porcine stomach mucuous, $1 / 10000$, P-7000).

The gastric juice and the bread media were centrifuged at $3000 \mathrm{rpm}$ for $10 \mathrm{~min}$, and the supernatants were kept at -20 ${ }^{\circ} \mathrm{C}$ before being used for PEG solutions.

Samples resulting from an in vitro gastric digestion were prepared from bread ground as previously described. PEG and phosphate buffer ( $5 \mathrm{mM}, \mathrm{CaCl}_{2} 4 \mathrm{mM}, \mathrm{NaCl} 1 \mathrm{M}, \mathrm{pH} 6.9$ ) were added to the ground bread to obtain a bread dry matter/liquid ratio of $0.22(\mathrm{w} / \mathrm{w})$ and a PEG concentration of $10 \mathrm{~g} \mathrm{~L}^{-1}$. The mixture was submitted to an amylase digestion (200 units/g of bread starch) for $6 \mathrm{~min}$ at $37{ }^{\circ} \mathrm{C}$ ( $\alpha$-amylase; porcine pancreas, 30000 units/glass, $150 \mathrm{mg}$ ), and the gastric in vitro digestion was performed under physiological conditions. The acidity of the medium $(\mathrm{HCl}, 0.2 \mathrm{~N})$, the pepsin addition, and the emptying of digesta were controlled by using peristaltic pumps connected to a computer. The regulation of the medium was monitored by predetermined curves ( $\mathrm{pH}$, pepsin concentration, emptying). The gastric contents were collected every $30 \mathrm{~min}$ during a $4 \mathrm{~h}$ period. The samples were centrifuged for $15 \mathrm{~min}$ at $4000 \mathrm{rpm}$, and the supernatants were kept for spectroscopic analyses.

Spectral Data. The infrared spectra were collected with a Fourier transform spectrometer (IFS25, Bruker) equipped with a horizontal attenuated total reflectance (ATR) cell (SPECAC). The ATR cell was made of a $\mathrm{ZnSe}$ crystal that presented an incidence angle of $45^{\circ}$. The liquid samples $(0.3$ mL) were placed in contact with the crystal at room temperature. Each spectrum was recorded between 4000 and 600 $\mathrm{cm}^{-1}$ at $2 \mathrm{~cm}^{-1}$ intervals and was the result of 64 scans. The $\mathrm{pH}$ values of the samples were checked and adjusted to about 6.5-7.0 prior to the recording of the spectra.

The mid-infrared spectra were split up into calibration and verification sets. Both the calibration and verification collections included spectra for the different PEG series. A detailed presentation of the spectral collections is given in Table 1.

Pretreatment of Spectral Data. The baselines of the spectra were corrected by using the software (SPECTRAFILE IR) supplied with the spectrometer. The correction for each spectrum consisted in subtracting the minimum absorbance value from every data point. A normalization of the spectrum to 2 absorbance units was thereafter performed.

Mathematical Treatment. Principal component analyses (Foucart, 1982) were performed on a COMPAQ microcomputer. This multivariate data treatment makes it possible to describe tables of data using a number of synthetic variables called principal components. The principal components are linear combinations of the original variables (wavenumbers) and present the advantage of being orthogonal. They are assessed to take into account maximum of variances. Each principal component is numbered according to the size of its corresponding variance; i.e., principal component 1 takes account of higher variance than does principal component 2.

A spectrum defined by $n$ wavenumbers can be seen as a point in an $n$-dimensional space. Similarly, a set of spectra forms a multidimensional volume in that space. By applying a principal component analysis, a new and more suitable system of axes is calculated. A first improvement is obtained

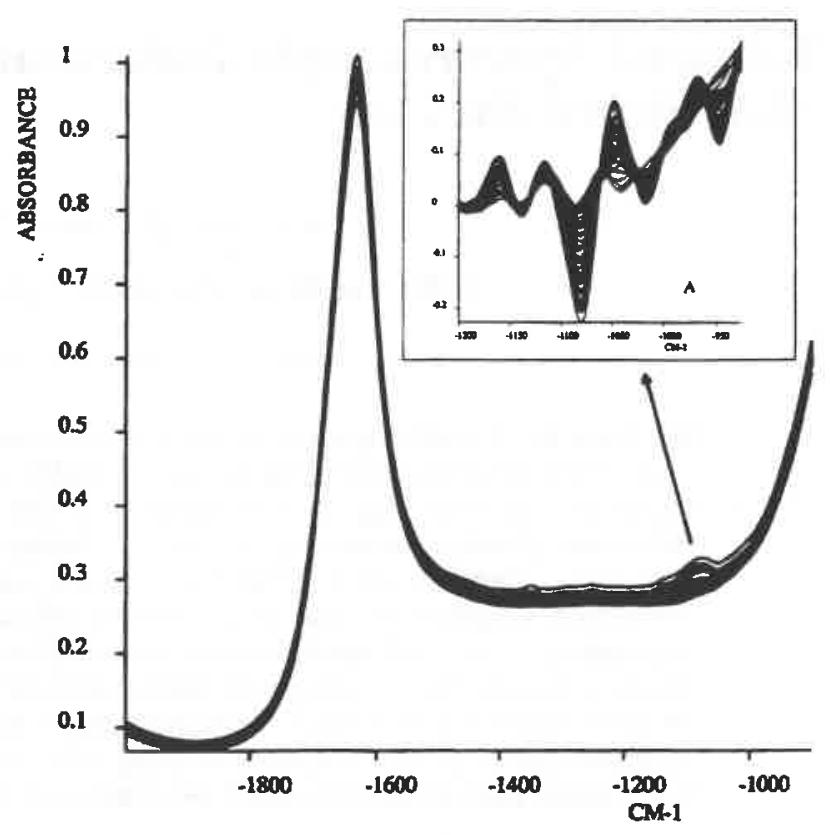

Figure 1. Infrared spectra of PEG aqueous solutions: (A) second-derivative spectra.

by putting the origin of the axes at the center of the multidimensional volume. This is performed by subtracting the mean infrared spectrum of the collection from each individual spectrum. A rotation of the axes is then performed to put the first axis (principal component 1) in the largest dimension of the volume. The second principal component is assessed to be orthogonal to the first one and is adjusted to the largest remaining dimension. Subsequent principal components are determined in the same way.

As a result, principal component analysis makes it possible to obtain similarity maps in which spectra resembling each other are neighboring. Moreover, a spectral interpretation of the similarities can be achieved by studying the eigenvectors associated with the principal components (Le Nouvel, 1981). The relevance of principal component analysis to study nearinfrared spectra has already been tested (Cowe and McNicol, 1985; Robert et al., 1987).

An equation of prediction was derived by applying a multiple linear stepwise regression to the calibration samples and using the principal components as independent variables. The efficiency of the equation was evaluated both by the standard errors of calibration (SEC) and standard errors of prediction (SEP):

$$
\begin{gathered}
\operatorname{SEC}=\sqrt{\sum_{i=1}^{n}\left(Y_{i}-Y_{i}^{\prime}\right)^{2} /(n-k-1)} \\
\operatorname{SEP}=\sqrt{\sum_{i=1}^{m}\left(Y_{i}-Y_{i}\right)^{2} / m}
\end{gathered}
$$

where $n$ and $m$ are the numbers of calibration and verification spectra, respectively, $Y_{i}$ and $Y_{i}$ are the observed and predicted values for the sample $i$, and $k$ is the number of independent variables in the equation of prediction.

\section{RESULTS AND DISCUSSION}

The mid-infrared spectra $\left(2000-900 \mathrm{~cm}^{-1}\right)$ of PEG in aqueous solutions are given in Figure 1. The spectra revealed an absorption band at $1638 \mathrm{~cm}^{-1}$ which is characteristic of water molecules. This wavenumber was more precisely assigned to the $\mathrm{O}-\mathrm{H}$ bending mode. A small absorption band was also observed around 1080 


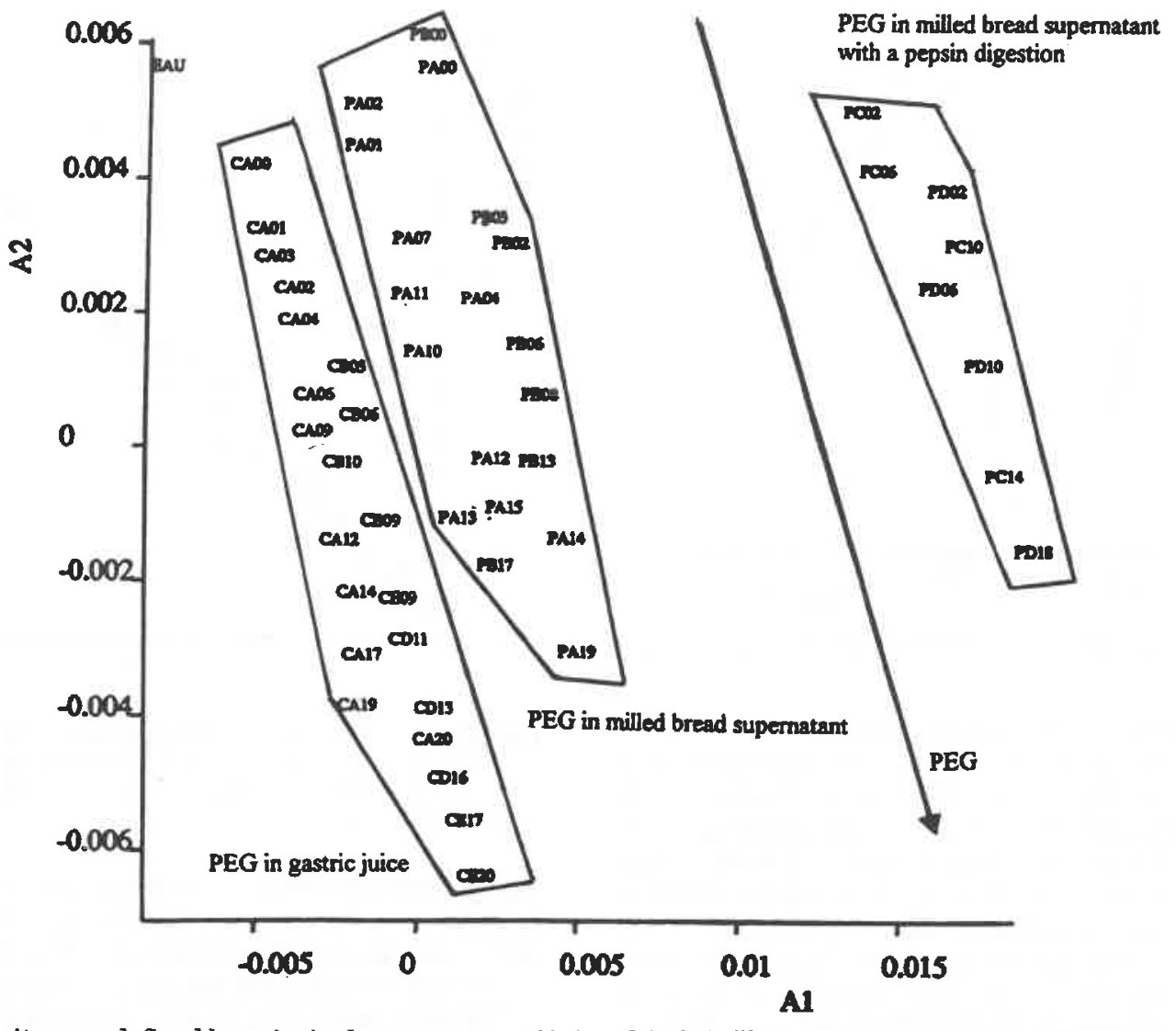

Figure 2. Similarity map defined by principal components 1 (A1) and 2 (A2). The arrow indicates an increase of the PEG content.

$\mathrm{cm}^{-1}$. This band, which characterized PEG molecules, could be assigned to the $\mathrm{C}-\mathrm{O}$ stretching mode. A better insight into the main absorption bands of PEG was obtained by studying the second-derivative spectra in the $1200-900 \mathrm{~cm}^{-1}$ region. In addition to the wavenumber at $1080 \mathrm{~cm}^{-1}, \mathrm{PEG}$ molecules presented peaks at 1138,1018 , and $944 \mathrm{~cm}^{-1}$. As the intensity of the absorption band at $1080 \mathrm{~cm}^{-1}$ increased with increasing PEG concentration in the solutions, the spectral region between 1100 and $1050 \mathrm{~cm}^{-1}$ may be useful for the determination of PEG content in digesta. However, the in vitro digesta obtained from the degradation of bread are complex media that contain protein and carbohydrate molecules. Proteins and carbohydrates both absorb in the mid-infrared range and may disturb or overlap the peaks characteristic of PEG. The absorption bands of proteins are observed around 1650, 1550, 1270, and $675 \mathrm{~cm}^{-1}$. In this case, no interference with the absorption band of PEG is expected. On the contrary, carbohydrates show numerous absorption bands between 1200 and $900 \mathrm{~cm}^{-1}$ (Robert et al., 1993) that can overlap the infrared spectrum of PEG. These bands involve more than a localized vibration and cannot be easily assigned to a specific functional group within carbohydrate molecules.

The efficiency of infrared spectroscopy to characterize the PEG content in complex media was tested by applying a principal component analysis to the calibration spectra recorded between 900 and $1200 \mathrm{~cm}^{-1}$. The first two principal components took $78.5 \%$ (principal component 1) and $15.0 \%$ (principal component 2) of the total variance into account. Both the spectra for the calibration and verification sets were projected onto the similarity map shown in Figure 2. A discrimination of the samples according to their nature was observed along principal component 1 . The samples correspond-

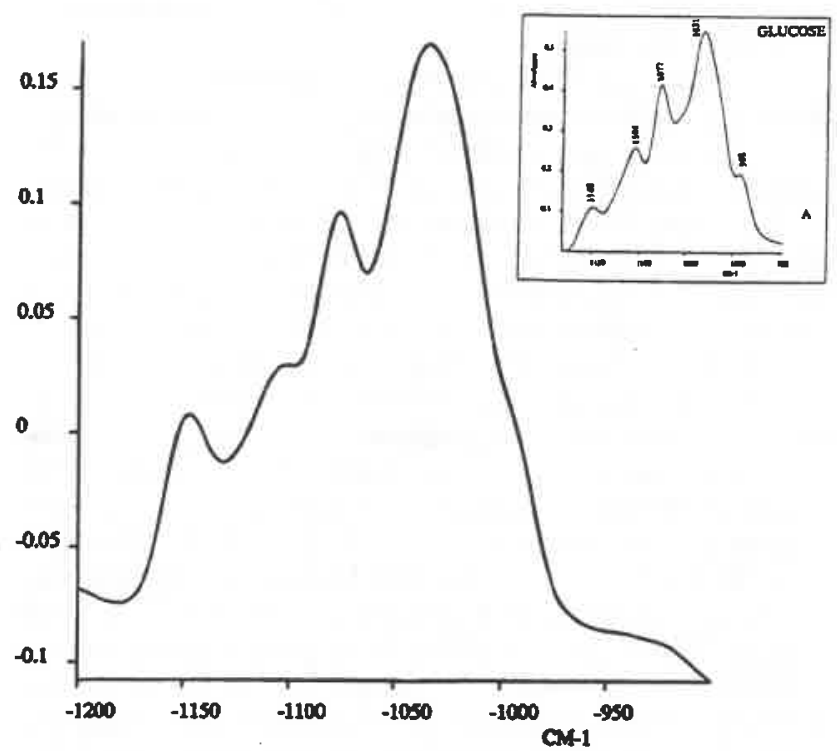

Figure 3. Spectral pattern associated to principal component 1: (A) infrared spectrum of a glucose solution.

ing to PEG in gastric juice were opposed to the samples in which PEG was mixed with bread degraded by pepsin. For each cluster, the samples were spread along principal component 2 according to PEG content. It therefore seemed that mid-infrared spectroscopy could be useful to predict the PEG content in digesta. A spectral interpretation of the discrimination of the samples was attempted by studying the eigenvectors. The spectral pattern associated with principal component 1 (Figure 3) presented similarities with the spectrum of glucose in aqueous solution. The spectral pattern, like the spectrum of glucose, was characterized 


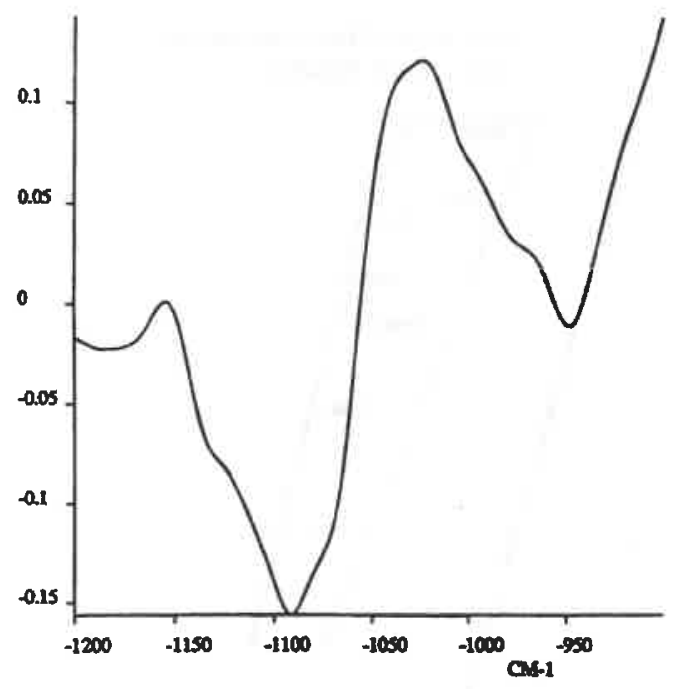

Figure 4. Spectral pattern associated with principal component 2.

by bands at $1148,1104,1078$, and $1031 \mathrm{~cm}^{-1}$. This result suggested that the bread samples degraded with pepsin presented higher concentrations of soluble carbohydrates. Indeed, the soluble sugar contents were $16.71 \%(\mathrm{w} / \mathrm{w})$ for bread samples that had been hydrolyzed by pepsin and $10.41 \%$ (w/w) for samples that had not. Negative peaks around 1090 and $946 \mathrm{~cm}^{-1}$ were observed for the eigenvector corresponding to principal component 2 (Figure 4). As these wavenumbers were observed for the second derivative spectra of PEG in aqueous solutions, principal component analysis seemed to make the identification of PEG from carbohydrate molecules possible.

To predict the PEG content, an equation was derived from the calibration samples by taking the principal components as independent variables into account. The correlation coefficient and the $F$ Fisher test gave values of 0.99 and 1670 , respectively ( 6 and 88 degrees of freedom). The equation of prediction was therefore significant at a probability level of $95 \%$. Moreover, both the standard deviations SEC and SEP were $0.29 \mathrm{~g} \mathrm{~L}^{-1}$ and confirmed the efficiency of mid infrared spectroscopy for predicting PEG content. A comparison of the observed data with the predicted values for the verification samples is shown in Figure 5. The principal components were introduced into the equation of prediction in the following order: $2,3,1,4,5,7$. The first principal component (principal component 2) that was taken into account was already assigned to PEG molecules. The coefficient of the third principal component (principal component 1) in the prediction equation was positive. Some interferences between PEG and oligosaccharides could, therefore, be expected when PEG content is predicted by infrared spectroscopy. An examination of bias, however, between observed and predicted values did not reveal particular trends for the different media. Consequently, the regression equation was thought to be adquate for the groups of samples studied.

A study of PEG in gastric conditions was attempted by using infrared spectroscopy. The analyzed samples were taken from an in vitro gastric digestion of bread.

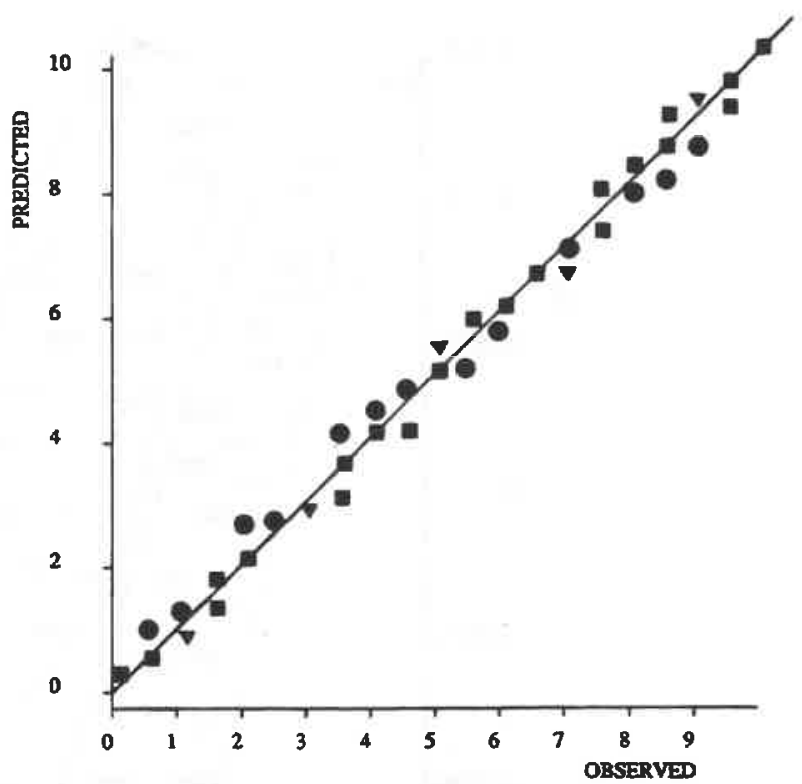

Figure 5. Prediction of PEG content for the verification samples and comparison with observed values: (II) gastric juice; (๑) milled bread supernatant; $(\nabla)$ milled bread supernatant with pepsin digestion.

The projection of the infrared spectra onto the similarity map previously assessed showed that the PEG content decreased with time (Figure 6). The sample obtained at $30 \mathrm{~min}$ was clearly opposed to the sample collected at $240 \mathrm{~min}$ according to principal component 2. Moreover, the discrimination of the samples along principal component 1 revealed that the oligosaccharide concentration in the liquid phase also decreased with time. Starch was partly degraded into maltose and maltotriose during the in vitro amylase hydrolysis simulating digestion in the mouth (Mörmann et al., 1982). In the stomach, starch degradation continued for a while in spite of the acidic conditions that did not favor the amylase activity. It is known, however, that $\mathrm{pH}$ in the stomach rises to about 6 during the first hour of the postpandrial period (Bauerfiend et al., 1990). Moreover, starchy substrates can also preserve the amylase activity in an acid medium (Lebenthal, 1987; Rosemblaum et al., 1988). The oligosaccharides resulting from this amylase activity were mainly evacuated in the liquid phase during the first minutes of gastric emptying. A determination of PEG content in the liquid phase was performed by applying the prediction equation. The results obtained when using the six principal components previously selected were overestimated (Table 2). This overestimation of PEG concentration could be explained by the introduction of principal component 1 into the equation. A new prediction of PEG content was therefore processed with only the first two principal components that were involved in the prediction equation. In this way, more relevant results were obtained. The PEG content (Figure 7) mainly decreased during the first $150 \mathrm{~min}$. This determination of PEG content during an in vitro gastric digestion corresponded well with the gastric emptying of the liquid phase. The coefficient of determination between the emptying of the liquid phase and the PEG concentration was $r^{2}=0.92$.

Table 2. PEG Content Prediction Using Six Principal Components for an in Vitro Digestion of Bread

\begin{tabular}{lllllllll}
\hline & EA30 & EA60 & EA90 & EA120 & EA150 & EA180 & EA210 & EA240 \\
\hline time $(\min )$ & 30 & 60 & 90 & 120 & 150 & 180 & 210 & 240 \\
PEG $\left(\mathrm{g} \mathrm{L}^{-1}\right)$ & 14.56 & 9.15 & 7.03 & 4.89 & 3.25 & 2.35 & 1.35 & 0.66
\end{tabular}




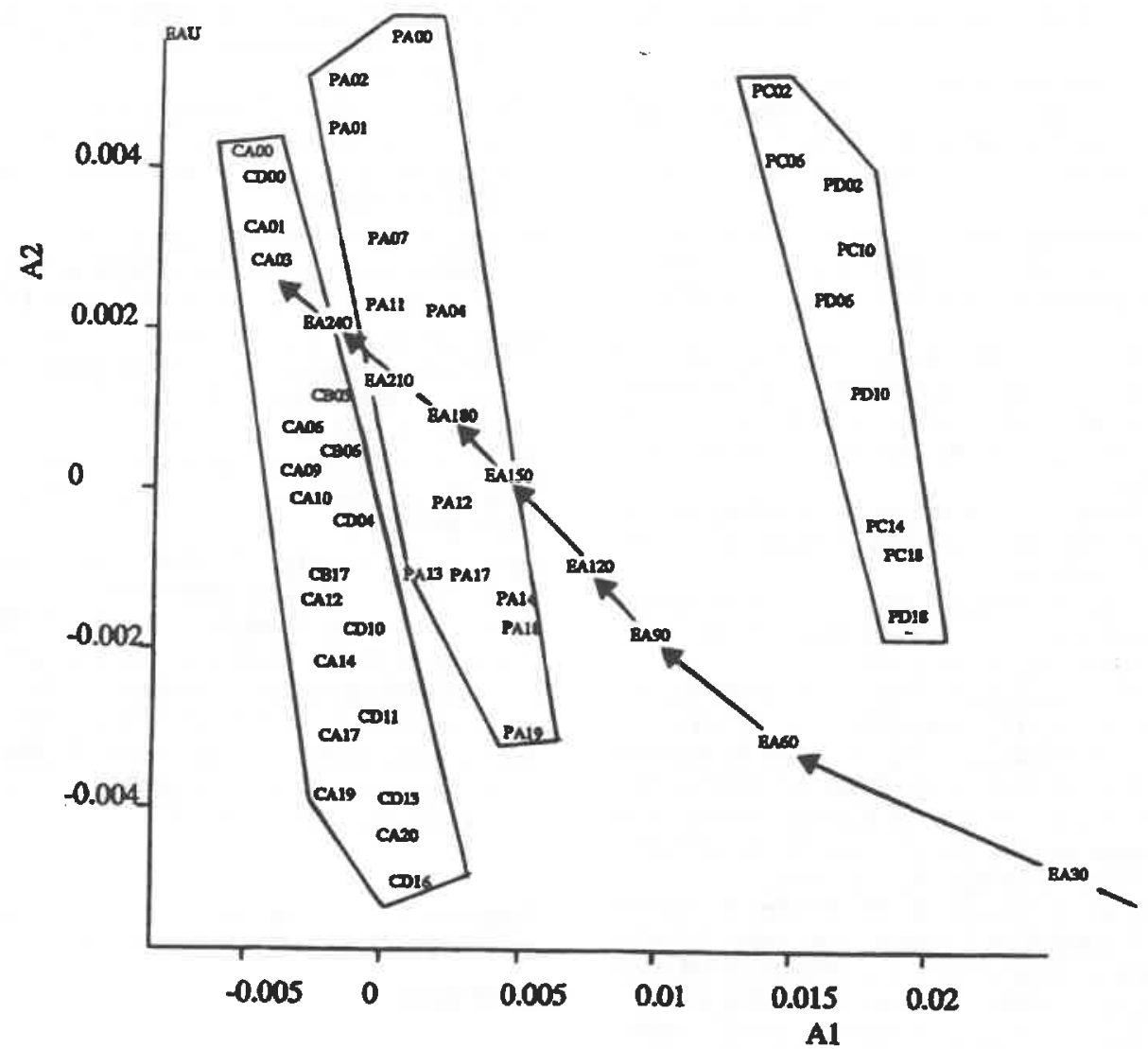

Figure 6. Bread in vitro digestion. The spectra are projected onto the similarity map.

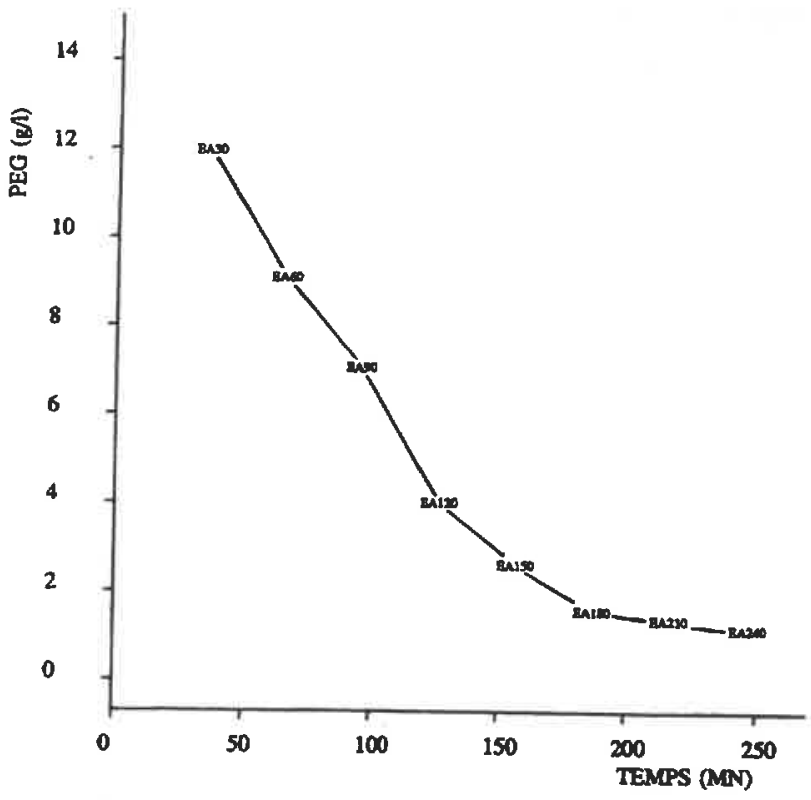

Figure 7. Bread in vitro digestion and prediction of the PEG content.

Although a definitive prediction equation of PEG content in various digesta was not established, the results obtained in this study showed that infrared spectroscopy could be a rapid alternative procedure for measuring gastric emptying with minimal sample preparation. Further work should take other constituents such as dietary fiber, known to pose problems of matrix in PEG determination, into account. A prediction equation that integrates the dietary fiber interaction would allow other applications of PEG analysis by infrared spectroscopy in nutrition studies (Makkar et al., 1995).

\section{LITERATURE CITED}

Bauerfeind, P.; Cilluffo, T.; Armstrong, D.; Emde, C.; MüllerDuying, W.; Duroux, P.; Blum, A. L. Fate of antiacid gel in the stomach site of action and interaction with food. Dig. Dis. Sci. 1990, 35, 553-558.

Coleman, S. W.; Murray I. The use of near-infrared reflectance spectroscopy to define nutrient digestion of hay by cattle. Anim. Feed Sci. Technol. 1993, 44, 137-149.

Cosgrove, G. P.; Burns, J. C.; Fisher, D. S.; Mueller, J. P.; Pond, K. R. Near infrared reflectance spectroscopy prediction of quality from masticated temperate forage species. Crop Sci. 1994, 34, 789-792.

Cowe, I. A.; McNicol, J. W. The use of principal components in the analysis of near infrared spectra. Appl. Spectrose. 1985, 39, 257-266.

Faisant, N.; Buléon, A.; Colonna, P.; Molis, C.; Lartique, S.; Galmiche, J. P.; Champ, M. Digestion of raw banana starch in the small intestine of healthy humans; structural features of resistant starch. Br. J. Nutr. 1995, in press.

Flourié, B.; Leblond, A.; Florent, C.; Ratureau, M.; Bissalli, A.; Rambaud, J. C. Starch malasorption and breath gas excretion in healthy human consuming low and high starch diets. Gastroenterology 1988, 95, 356-363.

Foucart, T. Analyse factorielle, Programmation sur microordinateur; Masson: Paris, 1982.

Fredstrom, S. B.; Jung, H. J. G.; Halgerson, J. L.; Eyden, C. A; Slavin, J. L. Trial of near infrared reflectance spectroscopy in a human fiber digestibility study. J. Agric. Food Chem. 1994, 42, 735-738.

Hyden, S. A turbidimetric method for the determination of higher polyethylene glycols in biological materials. Ann. $R$. Agric. Coll. Swed. 1955, 22, 139-145.

Isikawa, S.; Furuichi, Y. Reliability of polyethyleneglycol as an indicator for digestion studies with swine. Part II. Variation of polyethyleneglycol excretion and estimate of digestibility. Agric. Biol. Chem. 1968, 32, 1086-1092.

Jian, R.; Pecking, A.; Najean, Y.; Bernier, J. J. Study of the progression of an ordinary meal in the human small bowel 
by a scintigraphic method. Gastroenterol. Clin. Biol. 1979, $3,755-762$.

Kerlin, P.; Philips, S. Differential transit of liquids and solid residues through the human ileum. Am. J. Physiol. (Gastroenterol. Liver Physiol. 8) 1983, 245, G38-G43.

Laplace, J. P. Digestive transit in monogastric. Ann. Zootech. $1972,21,83-105$.

Lebenthal, E. Role of salivary amylas in gastric and intestinal digestion of starch. Dig. Dis. Sci. 1987, 32, 1155-1157.

Le Nouvel, J. Thése de 3éme cycle, Université de Rennes I, France, 1981

Makkar, H. P. S.; Blümmel, M.; Becker, K Formation of complexes between polyvinyl pyrrolidones or polyethylene glycols and tannins, and their implication in gas production and true digestibility in in vitro techniques. Br. J. Nutr. 1995, 73, 897-913.

Malagelada, J. R. Quantification of gastric solid-liquid discrimination during digestion of ordinary meals. Gastroenterology 1977, 72, 1264-1267.

Meerof, J. C.; Go, V. L. W.; Philips, S. F. Control of gastric emptying by osmolality of duodenal contents in man. Gastroenterology 1979, 68, 1144-1151.

Molis, C.; Champ, M.; Flourié, B.; Pellier, F.; Colonna, P.; Kozlowski, F.; Rambaud, J.C.; Galmiche, J. P. Small intestinal digestibility of processed corn starches in healthy human subjects. Eur. J. Clin. Nutr. 1992, 46, S131-S132.

Mörmann, J. E.; Amado, R.; Neukon, H. Comparative studies on the in vitro alpha-amylolysis of different wheat starch products. Starch/Staerke 1982, 34, 121-124.

Murray, I.; Morrin, M.; Paterson, R. M.; Rooke, J. Rumen organic matter degradation kinetics from near infrared spectra. Proceedings, 6th International Conference on Near Infrared Spectroscopy, Lorne, Victoria, Australia, 1994.

Norris, K. H.; Kuenstner, J. T. Rapid measurement of analytes in whole blood with NIR transmittance. 6th International Conference on Near Infrared Spectroscopy, Lorne, Victoria, Australia, 1994.
Robert, P.; Bertrand, D.; Devaux, M. F. Multivariate analysis applied to near infrared spectra of milk. Anal. Chem. 1987, 59, 2187-2191.

Robert, P.; Bertin, C.; Bertrand, D. Rumen microbial degradation of beet root pulps. Application of infrared spectroscopy to the study of protein and pectin. J. Agric. Food Chem. 1989, 37, 624-627.

Robert, P. Devaux, M. F.; Qannari, A.; Safar, M. Mid and near infrared study of carbohydrates by canonical correlation analysis. J. Near Infrared Spectrosc. 1993, 1, 99-108.

Rosemblaum, J. L.; Irwin, C. L.; Alpers, D. H. Starch and glucose oligosaccharides protect salivary-type amylase activity at acid pH. Am. J. Physiol. (Gastrointest. Liver Physiol. 17) 1988,254, G775-G780.

Smith, R. H. Substances in the calf alimentary tract interfering in the determination of polyethylene glycol. Nature 1958, $26,260-261$.

Sperber, I. S.; Hyden, S.; Ekman, J. The use of polyethylene glycol as a reference substance in the study of ruminant digestion. Ann. R. Agric. Coll. Swed. 1953, 20, 337-344.

Thomforde, G. M.; Brown, M. L.; Malagelada, J. R. Practical solid and liquid phase markers for studying gastric emptying in man. J. Nucl. Med. Technol. 1985, 13, 11-14.

Weimer, K.; Graham, L. S.; Reedy, T.; Elashoff, J.; Meyer, J. H. Simultaneous gastric emptying of two solid foods. Gastroenterology 1981, 81, 257-266.

Received for review April 17, 1995. Revised manuscript received July 12,1995 . Accepted July 31,1995 . $^{\circ}$

JF950224E

- Abstract published in Advance ACS Abstracts, September 15, 1995. 